\title{
Fresh air
}

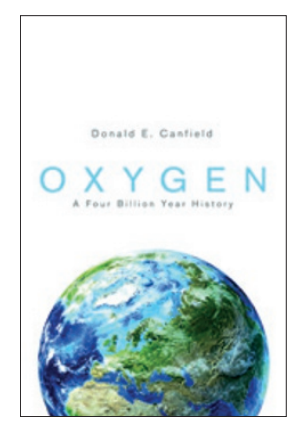

at the most extreme levels. Canfield's Oxygen is a rousing tour through time and space pitched from every essential angle - chemical, biological, geological and, most importantly, at the interface among these disciplines now known as 'biogeochemistry.' These are stories about a three-billion-year history of oxygen on Earth, but they are also an intimate look at those who make a living caring about oxygen.

The first step of the tour begins with one simple assumption: despite the potential for small amounts of $\mathrm{O}_{2}$ production by photodissociation of water without biology, the vast majority of $\mathrm{O}_{2}$ through Earth history is a by-product of photosynthesis. This innovation began with cyanobacteria and spread progressively across a bounty of life forms, including the proliferation of algae in the ocean and later the first greening of the continents a mere few hundreds of millions of years ago. Canfield, in some of his most thought-provoking chapters, takes us through discussions of life on Earth before oxygen and the earliest evolution of oxygenic photosynthesis. As the author tells us, we have learned a lot, but we are still only guessing at the beginnings of oxygenesis at roughly 2.5 to 3.0 billion years ago.

\section{Canfield steers skilfully, rigorously and entertainingly through the many debates and discoveries.}

Wonderful stories are emerging, as recounted by Canfield, to explain the possibility that the permanent accumulation of $\mathrm{O}_{2}$ in the atmosphere - at the so-called Great Oxidation Event - lagged the first biological production by hundreds of millions of years. Mysteries might be a better word, as we seek to extract primary fingerprints of $\mathrm{O}_{2}$ production and accumulation from the chemistry of rocks that have often suffered the overprinting offenses of billions of years of burial and deformation. If that's not enough to think about, $\mathrm{O}_{2}$ 'buffering' reactions that balanced the first biological $\mathrm{O}_{2}$ production with concomitant consumption may track the earliest formation of the continents, the distribution of volcanoes across Earth's surface, and even time-varying release of gases derived from much deeper layers in Earth's interior.

Some of the most compelling parts of Oxygen portray events relatively soon after the Great Oxidation Event - the so-called 'boring billion' years that were remarkable for their ability to put a throttle, if not a near chokehold, on the progression of life and the environment for a long time. Then the boring billion were busted, paving the way for things far less static - another rise in biospheric $\mathrm{O}_{2}$, the emergence of animals and other complex life, the formation and break-up of a supercontinent, and ice covering much if not most of the ocean and continents. Canfield explores the possible causes and effects among these phenomena and the door that opened finally to a mostly oxygenated atmosphere and oceans - the world we know today.

Canfield steers skilfully, rigorously and entertainingly through the many debates and discoveries, both old and new. In fact, never before have so many clever researchers turned their eyes towards the question of Earth's oxygen history and the inseparable co-evolution of life. The topic has become a cradle of novel biogeochemical techniques ranging from non-traditional metal isotope approaches to surprising mass-independent isotopic fractionations seen in sulfur to organic molecular fossils that leave your head spinning from their analytical challenges. Oxygen puts the reader right in the middle of all things new and exciting, while providing all the background necessary to make that centre accessible.

In so many ways, Oxygen is an examination of almost four billion years of early life pitched from the angle of oxygen's rise in the ocean and atmosphere. Charles Darwin was frustrated in his efforts to explain this initial explosion of animal life. He would be pleased to know that ancient rocks in fact reveal a much deeper history of environmental change and co-evolving ancestral life, both simple and complex, beneath a much younger animal-containing sedimentary veneer. The story of Oxygen is the story of our origins - and a breath of fresh air.

\section{REVIEWED BY TIMOTHY W. LYONS}

Timothy Lyons is a distinguished professor of biogeochemistry at the University of California, Riverside, USA. 